\title{
Particular clinical situation in a disease or syndrome
}

INSERM

\section{Source}

INSERM. (1999). Orphanet: an online rare disease and orphan drug data base. particular clinical situation in a disease or syndrome. ORPHA:377793

Clinical entity defined by a set of phenotypic abnormalities occurring in particular circumstances. 